\title{
Treatment with bimatoprost for exophthalmos in patients with inactive thyroid-associated ophthalmopathy
}

This article was published in the following Dove Press journal: Clinical Ophthalmology

\author{
Tomoaki Higashiyama \\ Masahito Ohji \\ Department of Ophthalmology, \\ Shiga University of Medical Science, \\ Otsu, Japan
}

\begin{abstract}
Purpose: This study was performed to observe changes prospectively in exophthalmos and orbital fat in patients with inactive thyroid-associated ophthalmopathy (TAO) treated with bimatoprost.

Methods: In this 12-month single-treatment pilot observational study, 13 patients with inactivephase TAO were administered bimatoprost to treat exophthalmos due to TAO. Exophthalmos values and orbital tissue volumes were measured on MRI by technicians in a masked fashion. Results: Nine orbits of nine patients (eight women, one man) were treated with bimatoprost for 12 months. Mean exophthalmos values before and after treatment were $21.7 \pm 2.2$ and $21.7 \pm 2.0 \mathrm{~mm}$, respectively. The mean value after 12 months of treatment was not significantly different from before treatment $(P=0.82)$. Mean orbital fat volume before and after 12 months of treatment was $17.2 \pm 2.5$ and $17.0 \pm 3.0 \mathrm{~cm}^{3}$, respectively. The corresponding total extraocular muscle volume was $4.0 \pm 0.7$ and $3.8 \pm 0.9 \mathrm{~cm}^{3}$, respectively. Mean volume in each tissue type after 12 months of treatment was not significantly different from before treatment (orbital fat, $P=0.70$; extraocular muscles, $P=0.32$ ).
\end{abstract}

Conclusion: Topical bimatoprost treatment did not reduce exophthalmos or orbital fat in this cohort of patients with inactive TAO.

Keywords: bimatoprost, thyroid-associated ophthalmopathy, exophthalmos, orbital fat

\section{Introduction}

Thyroid-associated ophthalmopathy (TAO) is an autoimmune inflammatory disease in the orbit that causes inflammation of extraocular muscle and orbital fat. ${ }^{1-5}$ Patients present with clinical symptoms and signs that may include exophthalmos, ocular movement disorder, upper-eyelid retraction, and chemosis..$^{5-9}$ The cause of exophthalmos, which decreases the quality of life of these patients, is mainly an increased amount of orbital fat and enlarged extraocular muscles. ${ }^{10}$

Methylprednisolone pulse therapy has been reported to reduce the inflammation associated with TAO. ${ }^{11-14}$ We have reported exophthalmos values and orbital tissue volume in patients with acute-phase TAO before and after methylprednisolone pulse therapy. ${ }^{15}$ Mean orbital fat volume did not change significantly, although extraocular muscle enlargement decreased significantly. As a result, the mean exophthalmos value was not significantly different after treatment, because the orbital fat volume, which is largest in the orbit, had not changed. Another study also showed that exophthalmos values did not significantly improve after methylprednisolone pulse therapy. ${ }^{16}$ Therefore, decreasing the amount of orbital fat appears to be the most important factor in alleviating exophthalmos, and studies have shown that orbital fat-decompression
Correspondence: Tomoaki Higashiyam Department of Ophthalmology, Shiga University of Medical Science, Seta,

Tsukinowa-cho, Otsu 520-2192, Japan

Tel +8I 775482276

Email higashi@belle.shiga-med.ac.jp 
surgery is effective for exophthalmos due to TAO. ${ }^{17,18}$ Another study showed that intravenous administration of teprotumumab, a human monoclonal antibody inhibitor of IGF1R, was effective for exophthalmos in patients with active TAO. ${ }^{19}$ IGF1R was detected in patients with TAO. Therefore, teprotumumab may result in a reduction in the volume of orbital fat.

Prostaglandin $\mathrm{F}_{2 \alpha}\left(\mathrm{PGF}_{2 \alpha}\right)$ analogues, such as bimatoprost, have been used in patients with glaucoma or hypertension. ${ }^{20,21}$ However, previous studies have shown that $\mathrm{PGF}_{2 \alpha}$ analogues can cause PG-associated periorbitopathy (PAP) such as enophthalmos, periorbital fat atrophy, and deepening of the upper-eyelid sulcus. ${ }^{22-26} \mathrm{PAP}$ has been reported more frequently after the use of bimatoprost than after the use of other $\mathrm{PGF}_{2 \alpha}$ analogues. ${ }^{27,28}$ Those studies reported the presence of enophthalmos and orbital fat atrophy in patients with glaucoma using bimatoprost. ${ }^{28,29}$ One study showed that $\mathrm{PGF}_{2 \alpha}$ prevented adipocyte differentiation by activating MAPK and that this mechanism might cause fat atrophy. ${ }^{29}$ To the best of our knowledge, however, changes in exophthalmos and orbital fat in patients with inactive TAO treated with bimatoprost have not been reported. Therefore, the purpose of this study was prospectively to observe changes in exophthalmos and orbital fat in patients with inactive TAO treated with bimatoprost.

\section{Methods}

\section{Patients}

Patients with inactive TAO who had developed exophthalmos were enrolled in this prospective interventional study at the Department of Ophthalmology, Shiga University of Medical Science Hospital from August 2015 to June 2018. The design was a 12-month single-treatment pilot observational study of bimatoprost in patients with inactive TAO. This study was approved by the institutional review board of Shiga University of Medical Science. It was conducted in accordance with the tenets of the Declaration of Helsinki. Written informed consent was obtained from each patient.

Exclusion criteria were the presence of TAO in the acute inflammatory phase, a history of treatment with $\mathrm{PGF}_{2 \alpha}$ analogues, a history of other orbital disease, such as that due to trauma, and/or being at risk for an MRI examination. The study group comprised 13 patients with inactive-phase TAO (13 orbits), whose mean \pm SD exophthalmos value before treatment was $21.7 \pm 1.9(16.6-24.8) \mathrm{mm}$.
MRI examinations were performed four times: before treatment and 3, 6, and 12 months after treatment. For each patient, if both orbits were treated with bimatoprost, only data for the right eye were used to avoid data duplication. The primary end point was change in exophthalmos values after 12 months of treatment. To meet the study objective, outcomes were measured not by clinical assessments, such as exophthalmometry, but entirely by MRI findings. Patients were treated for exophthalmos with bimatoprost ophthalmic solution $0.03 \%$ (Allergan, Irvine, CA, USA) once a day for 12 months. To avoid PAP-associated pigmentation, patients were instructed strictly to wipe off excess bimatoprost after eyedrop administration.

\section{MRI acquisition}

All images were acquired on a 3.0 Tesla MRI unit (Signa HDxt 3.0 T; GE Healthcare, Little Chalfont, UK) with a standard head coil. MR images were obtained using $T_{2}$-weighted spin-echo MRI with a slice thickness of $1.5 \mathrm{~mm}$. On axial images conditions were: repetition time $4,200 \mathrm{~ms}$, echo time $85 \mathrm{~ms}$, field of view $140 \mathrm{~mm}$, and number of excitations two. Those on coronal and sagittal images were: repetition time $5,000 \mathrm{~ms}$, echo time $85 \mathrm{~ms}$, field of view $140 \mathrm{~mm}$, and number of excitations two.

\section{Exophthalmos measurement}

Exophthalmos was measured on axial images using a workstation (Aquarius Intuition software; TeraRecon, Foster City, CA, USA), which was similar to that used in previous studies. ${ }^{15,30}$ The exophthalmos value was defined as the perpendicular distance from the top point of the corneal surface to the line between the bilateral frontal processes of the zygomatic bone (Figure 1). Exophthalmos was measured in a masked fashion by two technicians.

\section{Volume measurement}

The volume of each orbital tissue (ie, orbital fat, extraocular muscles, eyeball, optic nerve) were measured on MRI in a manner similar to that used in previous studies. ${ }^{15,31-33}$ Regions of interest (ROIs) were drawn around the tissue samples on the MR images, and cross-sectional areas of the ROIs were measured using the workstation. Cross-sectional areas of orbital fat, lateral rectus, medial rectus, and superior oblique muscles, eyeball, and optic nerve were captured on axial images (Figure 2). Areas of the superior rectus and inferior rectus muscles were evaluated on sagittal images. Coronal images were used to evaluate the inferior oblique muscle. 


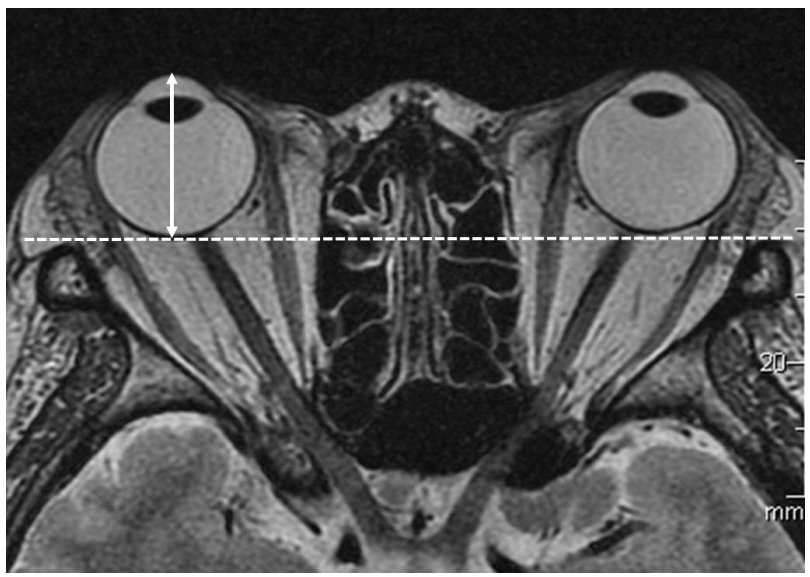

Figure I Exophthalmos measurement.

Note: Exophthalmos value was defined as the perpendicular distance from the top point of the corneal surface to the line between the bilateral frontal processes of the zygomatic bones.

ROIs of orbital fat included the lacrimal gland, vessels, and connective tissue, because these structures were difficult to separate. ROIs of the superior rectus muscle included the levator palpebrae muscle for the same reason. The volume of each tissue sample was calculated by multiplying the sum of the cross-sectional areas by the slice thickness $(1.5 \mathrm{~mm})$, and measured in a masked fashion by two technicians.

\section{Statistical analysis}

The Shapiro-Wilk test was used to test the normality of the numerical variables. Paired $t$-tests were used to compare the exophthalmos values and the orbital tissue volume before and after 12 months of treatment. All analyses were performed using SPSS 22 software (IBM, Armonk, NY, USA).
Data are expressed as means \pm SD. $P<0.05$ was considered to indicate statistical significance.

\section{Results \\ Patients}

In the final analysis, we analyzed nine orbits of nine patients (eight women, one man; mean age 49.9 \pm 10.6 [35-68] years) who had been treated with bimatoprost for 12 months. The mean pretreatment exophthalmos value was $21.7 \pm 2.2 \mathrm{~mm}$ (16.6-24.8). Five of the nine patients were treated bilaterally with bimatoprost, and four were treated unilaterally. All patients had Graves's disease, and four of the nine had a treatment history of methylprednisolone pulse therapy. No patients had a history of orbital surgery or orbital radiotherapy. Characteristics of the patients are listed in Table 1.

During the 12-month period, 4 of 13 patients dropped out of treatment (Figure 3). One of the four dropped out at 3 months because of the appearance of periocular skin hyperpigmentation. The second patient dropped out at 6 months because the TAO developed into an acute inflammatory phase. The third patient dropped out at 5 months because of stinging due to bimatoprost. Finally, the fourth patient dropped out at 6 months because of poor adherence to the regimen.

\section{Exophthalmos}

Mean exophthalmos values before and after 12 months of treatment are shown in Table 2. The mean value after 12 months was not significantly different from that before treatment (Figure 4).
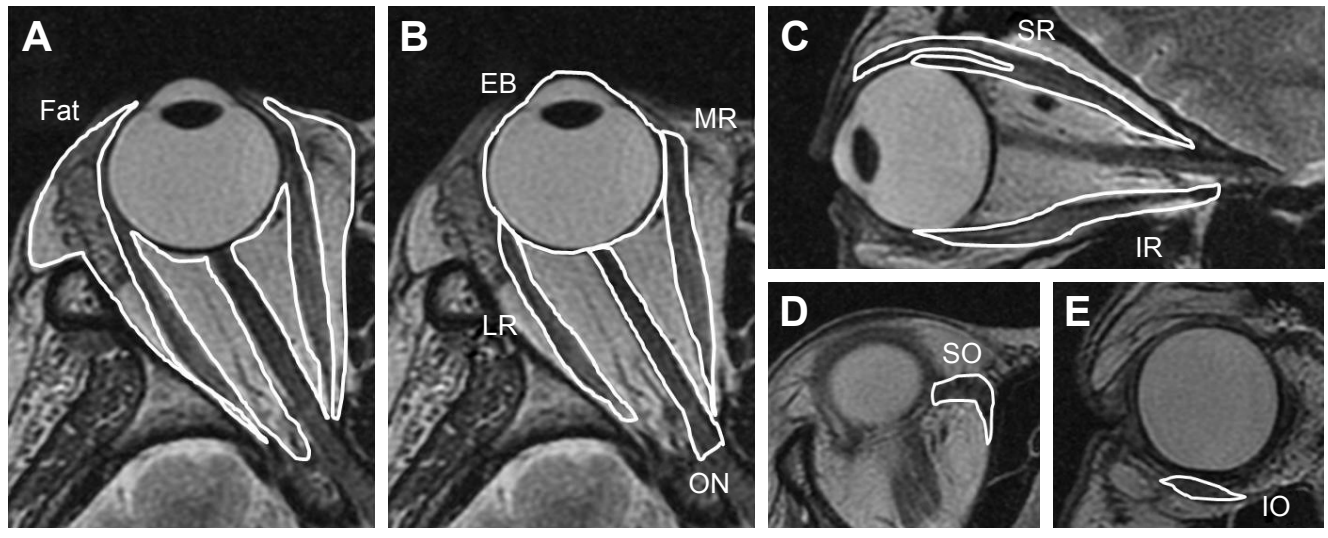

Figure 2 Volume measurement.

Notes: Regions of interest (ROIs) were drawn around tissue on MR images, and cross-sectional areas of the ROls were measured. The volume of each tissue type was calculated by multiplying the sum of the cross-sectional area by the slice thickness ( $1.5 \mathrm{~mm})$. (A) Axial slice shows cross-sectional areas of orbital fat (Fat). (B) Axial slice shows the cross-sectional areas of the lateral rectus (LR) and medial rectus (MR) muscles, eyeball (EB), and optic nerve (ON). (C) Sagittal slice shows the cross-sectional areas of the superior rectus (SR) and inferior rectus (IR) muscles. (D) Axial slice shows the cross-sectional area of the superior oblique (SO) muscle. (E) Coronal slice shows the cross-sectional areas of the inferior oblique (IO) muscle. 


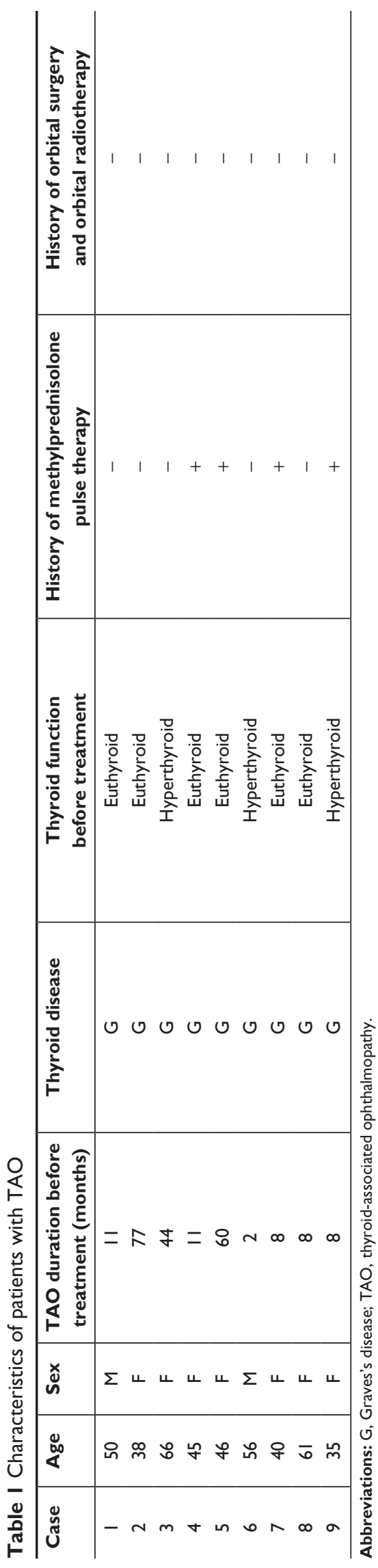

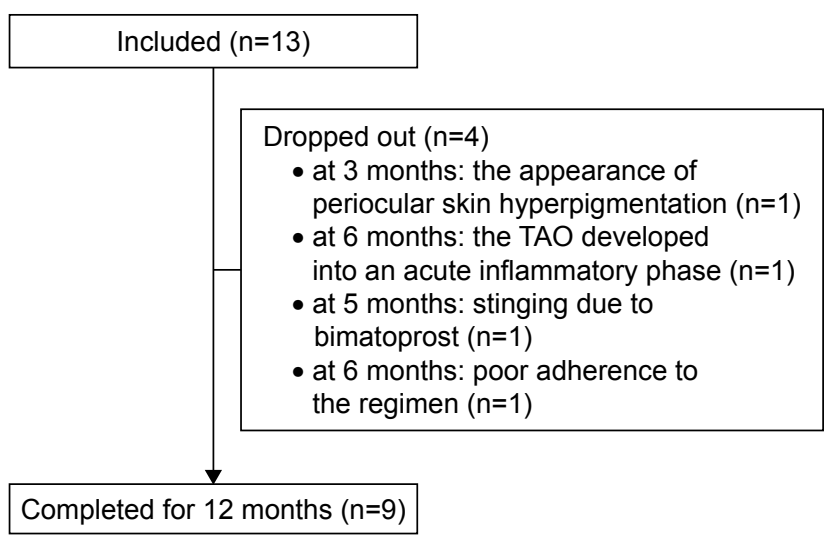

Figure 3 Diagram of patients who were included and dropped out. Notes: Thirteen patients were included in this study. Four of the 13 dropped out. In the final analysis, we analyzed nine orbits of nine patients. Abbreviation: TAO, thyroid-associated ophthalmopathy.

\section{Volume of orbital fat and extraocular muscles}

Mean volumes before and after 12 months of treatment are shown in Table 2. The mean volume of each tissue after 12 months of treatment was not significantly different from that before treatment (Figures 5 and 6).

\section{Patient dropout}

For patients who dropped out, orbital fat volume and exophthalmos values before treatment and at the last MRI examination are shown in Table 3 and Figures 4-6 (one patient was excluded from the table and figures because the TAO developed into an acute inflammatory phase and the extraocular muscles were swelling). Orbital fat volume and exophthalmos values for patients who dropped out were similar before treatment and at the last MRI examination.

\section{Discussion}

Our results indicate that neither the mean exophthalmos value nor mean orbital fat volume decreased significantly after 12 months of treatment with bimatoprost. Previous studies of patients with TAO showed a close relationship between exophthalmos values and volume of orbital fat. ${ }^{30,34}$ Based on these findings, a decrease in orbital fat is needed to alleviate exophthalmos. Other studies have revealed the effectiveness of surgery (eg, orbital fat decompression) to accomplish this difference. ${ }^{17,18}$ Richter et $a l^{17}$ reported the effectiveness of transpalpebral decompression. Their mean resected volume of orbital fat was $6.3 \mathrm{~cm}^{3}$, and their mean exophthalmos value decreased by $5.9 \mathrm{~mm}$ (from $24.3 \mathrm{~mm}$ preoperatively 
Table 2 Changes in exophthalmos values and orbital tissue volume from before to after treatment with bimatoprost

\begin{tabular}{l|c|c|c|c|c}
\hline & $\begin{array}{c}\text { Before } \\
\text { treatment }\end{array}$ & $\begin{array}{c}\text { After I2 months } \\
\text { of treatment }\end{array}$ & Change value & 95\% Cl & P-value \\
\hline Exophthalmos $(\mathrm{mm})$ & $21.7 \pm 2.2$ & $21.7 \pm 2.0$ & $0.05 \pm 0.7 \mathrm{I}$ & -0.60 to 0.49 & 0.82 \\
Orbital fat $\left(\mathrm{cm}^{3}\right)$ & $17.2 \pm 2.5$ & $17.0 \pm 3.0$ & $-0.13 \pm 0.94$ & -0.60 to 0.85 & 0.70 \\
Total extraocular muscles $\left(\mathrm{cm}^{3}\right)$ & $4.0 \pm 0.7$ & $3.8 \pm 0.9$ & $-0.21 \pm 0.59$ & -0.25 to 0.66 & 0.32 \\
Eyeball $\left(\mathrm{cm}^{3}\right)$ & $9.3 \pm 1.1$ & $9.3 \pm 0.9$ & $-0.07 \pm 0.38$ & -0.22 to 0.36 & 0.60 \\
Optic nerve $\left(\mathrm{cm}^{3}\right)$ & $0.5 \pm 0.1$ & $0.4 \pm 0.1$ & $-0.05 \pm 0.12$ & -0.48 to 0.14 & 0.29 \\
\hline
\end{tabular}

to $18.4 \mathrm{~mm}$ postoperatively). It decreased according to the decrease in the orbital fat volume postoperatively. In the current study, we performed a new treatment using noninvasive bimatoprost. Unfortunately, exophthalmos values were not lower after treatment, because orbital fat volume had not decreased.

Although a previous study showed orbital fat atrophy in patients with glaucoma after using bimatoprost, ${ }^{28,29}$ we did not have the same experience in our patients with TAO. The most important regulators of fat-cell lipolysis are hormones and paracrine factors, such as prostaglandins. ${ }^{35}$ $\mathrm{PGF}_{2 \alpha}$-receptor agonists are potent inhibitors of adipocyte differentiation. ${ }^{36-38}$ Taketani et al ${ }^{39}$ reported that $\mathrm{PGF}_{20}$ analogues have the potential to inhibit adipogenesis in vitro through $\mathrm{PGF}_{2 \alpha}$-receptor stimulation. The orbital fat atrophy reported in the patients with glaucoma treated with bimatoprost might have occurred by that mechanism. In the current study, however, the volume of orbital fat had not decreased after treatment. Although the reason is unclear, we speculate that the pathophysiology associated with TAO might be different from that associated with glaucoma.

Four of 13 patients dropped out of this study. The reasons were adverse effects and intolerance of bimatoprost because of the development of periocular skin hyperpigmentation and bimatoprost-induced stinging. PAP has been reported more

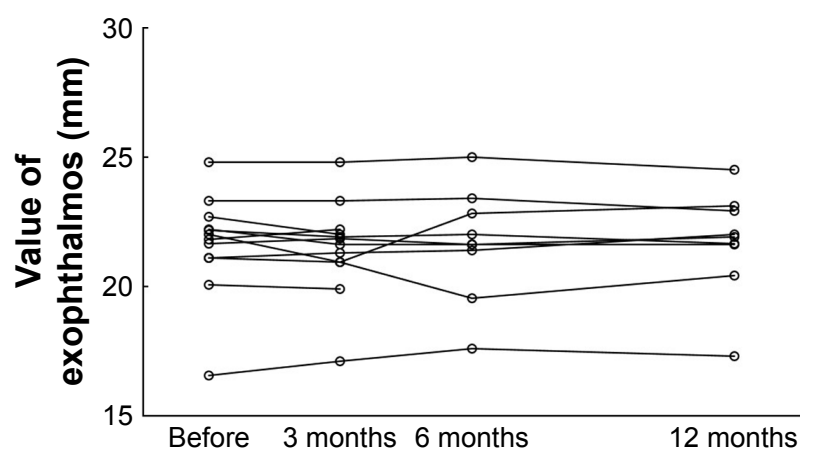

Figure 4 Exophthalmos values.

Note: Mean values after 12 months of treatment were not significantly different from those before treatment $(P=0.82)$. frequently after using bimatoprost than after use of other $\mathrm{PGF}_{2 \alpha}$ analogues, ${ }^{34,35}$ hence the dropouts.

The present study has some limitations. First, the sample was small. Although only nine orbits were included in this study, the results showed a similar tendency in all patients, and exophthalmos values and orbital fat volume after 12 months of treatment were not remarkably different from those before treatment. Second, only bimatoprost was used. Other $\mathrm{PGF}_{2 \alpha}$ analogues, such as latanoprost, were not evaluated in this study. However, it is expected that other $\mathrm{PGF}_{2 \alpha}$ analogues will be ineffective in reducing exophthalmos in patients with TAO, because the incidence of PAP caused by bimatoprost is higher than that caused by other $\mathrm{PGF}_{2 \alpha}$ analogues. ${ }^{27,28}$ Third, we used eyedrops as the method of administration in this study, because previous studies have shown that bimatoprost eyedrops cause enophthalmos in patients with glaucoma. ${ }^{28,29}$ Actually, bimatoprost eyedrops were ineffective for TAO-induced exophthalmos in the present study. Therefore, because the cause of ineffectiveness in this study might have been eyedrops as the method of administration, it cannot be denied that other methods of bimatoprost administration could be effective. Fourth, cytokines stimulate orbital fibroblasts to produce high levels of $\mathrm{PGE}_{2}$ in patients with TAO, enlarging the volume of orbital fat and extraocular muscle. ${ }^{11,40-42}$ This mechanism,

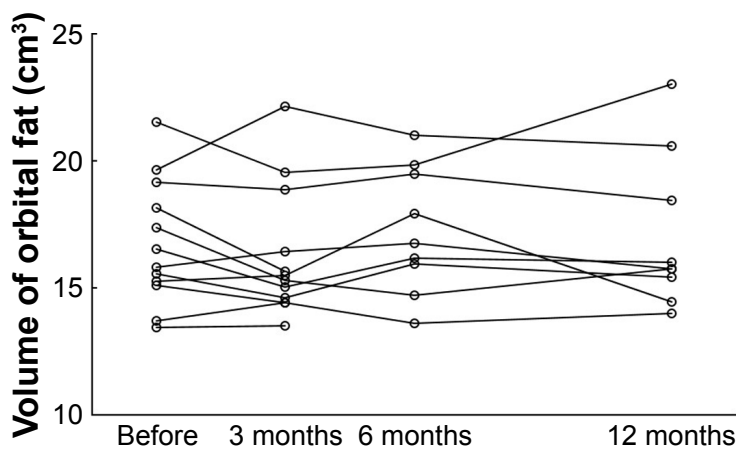

Figure 5 Orbital fat volume.

Note: Mean volume after 12 months of treatment was not significantly different from that before treatment $(P=0.70)$. 


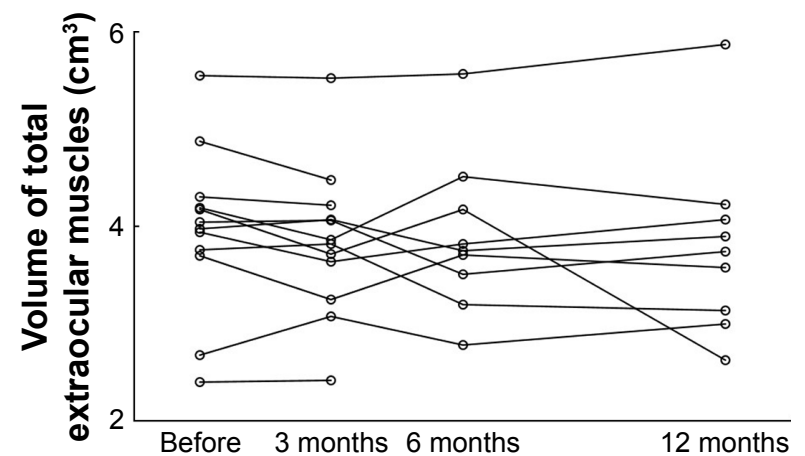

Figure 6 Extraocular muscle volume.

Note: Mean volume after 12 months of treatment was not significantly different from that before treatment $(P=0.32)$.

which differs from that in normal individuals and patients with glaucoma, may be related to that in the present study of bimatoprost (ie, prostaglandin analogues).

In conclusion, mean exophthalmos values and orbital fat volume were not significantly lower after treatment with bimatoprost. Therefore, topical bimatoprost treatment did not reduce exophthalmos or orbital fat in this cohort of patients with inactive TAO.

\section{Acknowledgments}

We thank Ms Fumiko Kimura and Ms Yasuyo Hongo for measurements of volume and exophthalmos in this study. This work was supported by JSPS Kakenhi grant JP17K16966. We thank Nancy Schatken, BS, MT (ASCP) and Angela Morben, DVM, ELS from Edanz Group (www. edanzediting.com/ac) for editing a draft of this manuscript.

\section{Author contributions}

TH contributed to conception, design, data acquisition, analysis, and interpretation; drafted the article and revised it critically for important intellectual content; provided final approval of the version to be published; and agrees to be accountable for all aspects of the work in ensuring that questions related

Table 3 Exophthalmos values and orbital tissue volume from before treatment to last MRI examination in patients who dropped out

\begin{tabular}{l|c|c}
\hline & $\begin{array}{c}\text { Before } \\
\text { treatment }\end{array}$ & $\begin{array}{c}\text { At last } \\
\text { MRI }\end{array}$ \\
\hline Exophthalmos $(\mathrm{mm})$ & $21.5 \pm \mathrm{I} .3$ & $21.4 \pm \mathrm{I} .3$ \\
Orbital fat $\left(\mathrm{cm}^{3}\right)$ & $15.6 \pm 2.4$ & $14.5 \pm \mathrm{I} .1$ \\
Total extraocular muscles $\left(\mathrm{cm}^{3}\right)$ & $3.9 \pm 1.3$ & $3.7 \pm 1.1$ \\
Eyeball $\left(\mathrm{cm}^{3}\right)$ & $8.4 \pm 1.3$ & $8.6 \pm 1.2$ \\
Optic nerve $\left(\mathrm{cm}^{3}\right)$ & $0.5 \pm 0.1$ & $0.5 \pm 0.1$ \\
\hline
\end{tabular}

Abbreviation: MRI, magnetic resonance imaging. to the accuracy or integrity of the work are appropriately investigated and resolved. MO contributed to the conception and design of the study and the analysis and interpretation of data; revised it critically for important intellectual content; provided final approval of the version to be published; and agrees to be accountable for all aspects of the work in ensuring that questions related to the accuracy or integrity of the work are appropriately investigated and resolved.

\section{Disclosure}

TH reports grants from JSPS Kakenhi during the conduct of the study, personal fees from Senju Pharmaceutical and Pfizer Japan, grants from Alcon Japan, and grants from Novartis Pharmaceuticals outside the submitted work. MO reports grants and personal fees from Alcon Japan, Novartis Pharmaceuticals, Santen Pharmaceutical, Otsuka Pharmaceutical, Pfizer Japan, Hoya, and Senju Pharmaceutical, and personal fees from Allergan Japan, Bayer, Kowa Pharmaceutical Company, Chuo Sangio, Topcon, RE Medical, and Carl Zeiss Japan outside the submitted work. The authors report no other conflicts of interest in this work.

\section{References}

1. Hatton MP, Rubin PA. The pathophysiology of thyroid-associated ophthalmopathy. Ophthalmol Clin North Am. 2002;15(1):113-119.

2. El-Kaissi S, Frauman AG, Wall JR. Thyroid-associated ophthalmopathy: a practical guide to classification, natural history and management. Intern Med J. 2004;34(8):482-491.

3. Stein JD, Childers D, Gupta S, et al. Risk factors for developing thyroidassociated ophthalmopathy among individuals with Graves disease. JAMA Ophthalmol. 2015;133(3):290-296.

4. Higashiyama T, Nishida Y, Morino K, et al. Use of MRI signal intensity of extraocular muscles to evaluate methylprednisolone pulse therapy in thyroid-associated ophthalmopathy. Jpn J Ophthalmol. 2015;59(2): 124-130.

5. Higashiyama T, Iwasa M, Ohji M. Quantitative analysis of inflammation in orbital fat of thyroid-associated ophthalmopathy using MRI signal intensity. Sci Rep. 2017;7(1):16874.

6. Murakami Y, Kanamoto T, Tuboi T, Maeda T, Inoue Y. Evaluation of extraocular muscle enlargement in dysthyroid ophthalmopathy. Jpn J Ophthalmol. 2001;45(6):622-627.

7. Prummel MF, Bakker A, Wiersinga WM, et al. Multi-center study on the characteristics and treatment strategies of patients with Graves' orbitopathy: the first European Group on Graves' Orbitopathy experience. Eur J Endocrinol. 2003;148(5):491-495.

8. Bahn RS. Graves' ophthalmopathy. N Engl J Med. 2010;362(8):726-738.

9. Hiromatsu Y, Eguchi H, Tani J, Kasaoka M, Teshima Y. Graves' ophthalmopathy: epidemiology and natural history. Intern Med. 2014; 53(5):353-360.

10. Lehmann GM, Feldon SE, Smith TJ, Phipps RP. Immune mechanisms in thyroid eye disease. Thyroid. 2008;18(9):959-965.

11. Bartalena L, Baldeschi L, Dickinson A, et al. Consensus statement of the European Group on Graves' Orbitopathy (EUGOGO) on management of GO. Eur J Endocrinol. 2008;158(3):273-285.

12. Tortora F, Prudente M, Cirillo M, et al. Diagnostic accuracy of shorttime inversion recovery sequence in graves' ophthalmopathy before and after prednisone treatment. Neuroradiology. 2014;56(5):353-361. 
13. Higashiyama T, Nishida Y, Ohji M. Relationship between magnetic resonance imaging signal intensity and volume of extraocular muscles in thyroid-associated ophthalmopathy with methylprednisolone pulse therapy. Clin Ophthalmol. 2016;10:721-729.

14. Bartalena L, Baldeschi L, Boboridis K, et al. The 2016 European thyroid association/european group on graves' orbitopathy guidelines for the management of graves' orbitopathy. Eur Thyroid J. 2016;5(1):9-26.

15. Higashiyama T, Nishida Y, Ohji M. Changes of orbital tissue volumes and proptosis in patients with thyroid extraocular muscle swelling after methylprednisolone pulse therapy. Jpn J Ophthalmol. 2015;59(6): 430-435.

16. Ohtsuka K, Sato A, Kawaguchi S, Hashimoto M, Suzuki Y. Effect of high-dose intravenous steroid pulse therapy followed by 3-month oral steroid therapy for graves' ophthalmopathy. Jpn J Ophthalmol. 2002; 46(5):563-567.

17. Richter DF, Stoff A, Olivari N. Transpalpebral decompression of endocrine ophthalmopathy by intraorbital fat removal (Olivari technique): experience and progression after more than 3000 operations over 20 years. Plast Reconstr Surg. 2007;120(1):109-123.

18. Prat MC, Braunstein AL, Dagi Glass LR, Kazim M. Orbital fat decompression for thyroid eye disease: retrospective case review and criteria for optimal case selection. Ophthalmic Plast Reconstr Surg. 2015;31(3): 215-218.

19. Smith TJ, Kahaly GJ, Ezra DG, et al. Teprotumumab for thyroid-associated ophthalmopathy. N Engl J Med. 2017;376(18):1748-1761.

20. Wang K, Xu L, Yuan Z, et al. Intraocular pressure-lowering efficacy and safety of bimatoprost $0.03 \%$ therapy for primary open-angle glaucoma and ocular hypertension patients in China. BMC Ophthalmol. 2014; 14:21.

21. Li T, Lindsley K, Rouse B, et al. Comparative effectiveness of first-line medications for primary open-angle glaucoma: a systematic review and network meta-analysis. Ophthalmology. 2016;123(1):129-140.

22. Yang HK, Park KH, Kim TW, Kim DM. Deepening of eyelid superior sulcus during topical travoprost treatment. Jpn J Ophthalmol. 2009; 53(2):176-179.

23. Yoshino T, Fukuchi T, Togano T, et al. Eyelid and eyelash changes due to prostaglandin analog therapy in unilateral treatment cases. Jpn J Ophthalmol. 2013;57(2):172-178.

24. Sakata R, Shirato S, Miyata K, Aihara M. Incidence of deepening of the upper eyelid sulcus on treatment with a tafluprost ophthalmic solution. Jpn J Ophthalmol. 2014;58(2):212-217.

25. Nakakura S, Yamamoto M, Terao E, et al. Prostaglandin-associated periorbitopathy in latanoprost users. Clin Ophthalmol. 2015;9:51-56.

26. Rabinowitz MP, Katz LJ, Moster MR, et al. Unilateral prostaglandinassociated periorbitopathy: a syndrome involving upper eyelid retraction distinguishable from the aging sunken eyelid. Ophthalmic Plast Reconstr Surg. 2015;31(5):373-378.

27. Inoue K, Shiokawa M, Wakakura M, Tomita G. Deepening of the upper eyelid sulcus caused by 5 types of prostaglandin analogs. J Glaucoma. 2013;22(8):626-631.
28. Kucukevcilioglu M, Bayer A, Uysal Y, Altinsoy HI. Prostaglandin associated periorbitopathy in patients using bimatoprost, latanoprost and travoprost. Clin Exp Ophthalmol. 2014;42(2):126-131.

29. Jayaprakasam A, Ghazi-Nouri S. Periorbital fat atrophy - an unfamiliar side effect of prostaglandin analogues. Orbit. 2010;29(6):357-359.

30. Nishida Y, Tian S, Isberg B, et al. Significance of orbital fatty tissue for exophthalmos in thyroid-associated ophthalmopathy. Graefes Arch Clin Exp Ophthalmol. 2002;240(7):515-520.

31. Tian S, Nishida Y, Isberg B, Lennerstrand G. MRI measurements of normal extraocular muscles and other orbital structures. Graefes Arch Clin Exp Ophthalmol. 2000;238(5):393-404.

32. Nishida Y, Tian S, Isberg B, Tallstedt L, Lennerstrand G. MRI measurements of orbital tissues in dysthyroid ophthalmopathy. Graefes Arch Clin Exp Ophthalmol. 2001;239(11):824-831.

33. Lennerstrand G, Tian S, Isberg B, et al. Magnetic resonance imaging and ultrasound measurements of extraocular muscles in thyroid-associated ophthalmopathy at different stages of the disease. Acta Ophthalmol Scand. 2007;85(2):192-201.

34. Peyster RG, Ginsberg F, Silber JH, Adler LP. Exophthalmos caused by excessive fat: ct volumetric analysis and differential diagnosis. AJR Am J Roentgenol. 1986;146(3):459-464.

35. Arner P. Human fat cell lipolysis: biochemistry, regulation and clinical role. Best Pract Res Clin Endocrinol Metab. 2005;19(4):471-482.

36. Miller CW, Casimir DA, Ntambi JM. The mechanism of inhibition of 3T3-L1 preadipocyte differentiation by prostaglandin F2alpha. Endocrinology. 1996;137(12):5641-5650.

37. Serrero G, Lepak NM. Prostaglandin F2alpha receptor (FP receptor) agonists are potent adipose differentiation inhibitors for primary culture of adipocyte precursors in defined medium. Biochem Biophys Res Commun. 1997;233(1):200-202.

38. Liu L, Clipstone NA. Prostaglandin F2alpha inhibits adipocyte differentiation via a $\mathrm{G}$ alpha q-calcium-calcineurin-dependent signaling pathway. J Cell Biochem. 2007;100(1):161-173.

39. Taketani Y, Yamagishi R, Fujishiro T, et al. Activation of the prostanoid FP receptor inhibits adipogenesis leading to deepening of the upper eyelid sulcus in prostaglandin-associated periorbitopathy. Invest Ophthalmol Vis Sci. 2014;55(3):1269-1276.

40. Han R, Tsui S, Smith TJ. Up-regulation of prostaglandin E2 synthesis by interleukin-1beta in human orbital fibroblasts involves coordinate induction of prostaglandin-endoperoxide $\mathrm{H}$ synthase- 2 and glutathionedependent prostaglandin E2 synthase expression. J Biol Chem. 2002; 277(19):16355-16364.

41. Koumas L, Smith TJ, Phipps RP. Fibroblast subsets in the human orbit: Thy-1+ and Thy-1-subpopulations exhibit distinct phenotypes. Eur J Immunol. 2002;32(2):477-485.

42. Fang S, Huang Y, Zhong S, et al. Regulation of orbital fibrosis and adipogenesis by pathogenic th17 cells in graves orbitopathy. J Clin Endocrinol Metab. 2017;102(11):4273-4283.
Clinical Ophthalmology

\section{Publish your work in this journal}

Clinical Ophthalmology is an international, peer-reviewed journal covering all subspecialties within ophthalmology. Key topics include: Optometry; Visual science; Pharmacology and drug therapy in eye diseases; Basic Sciences; Primary and Secondary eye care; Patient Safety and Quality of Care Improvements. This journal is indexed on Submit your manuscript here: http://www.dovepress.com/clinical-ophthalmology-journal

\section{Dovepress}

PubMed Central and CAS, and is the official journal of The Society of Clinical Ophthalmology (SCO). The manuscript management system is completely online and includes a very quick and fair peer-review system, which is all easy to use. Visit http://www.dovepress.com/ testimonials.php to read real quotes from published authors. 